\title{
Communicating With the Motor Cortex? Cortisol and Yawning As Possible Biomarkers for the Detection of Neurological Disease
}

\section{Simon BN Thompson ${ }^{1,2,3}$}

${ }^{1}$ Faculty of Science and Technology, Bournemouth University, BH15 1YE, UK

${ }^{2}$ Dementia Institute, Bournemouth University, BH1 3LT, UK

${ }^{3}$ International Scientific Council for Research into Multiple Sclerosis, Université Paris Ouest Nanterre La Défense, 92000 Nanterre, France

Corresponding author: Simon BN Thompson, Faculty of Science and Technology, Bournemouth University, Poole House (P305), Poole, BH12 5BB, UK, Tel: +44 1202 961558; E-mail: simont@bournemouth.ac.uk

Received: Jul 20, 2016; Accepted: Jul 25, 2016; Published: Jul 29, 2016

Citation: Thompson SBN. Communicating with the Motor Cortex? Cortisol and Yawning as Possible Biomarkers for the Detection of Neurological Disease. J Neurol Neurosci. 2016, 7: S3.

\begin{abstract}
Cortisol and yawning have been proposed as new potential biomarkers for the early detection of signs of neurological disease. Recent evidence from neuroscience has shown that there is communication between the motor cortex and more remote but vital centres such as the brain-stem and hypothalamus. Hormonal as well as neuronal links form the prosed network that influences and monitors the regulation of cortisol and the regulation of brain temperature governed by the hypothalamus. This evidence tends to support the prosed linkage between brain-stem, hypothalamus and motor cortex and lends support for the Thompson Cortisol Hypothesis which proposes threshold levels of cortisol elicit yawning for brain cooling, and parakinesia brachialis oscitans, the observed arm movement seen in brain-stem ischaemic stroke patients during involuntary yawning.
\end{abstract}

Keywords: Motor cortex; Cortisol; Neurological disease; Cushing's disease; Multiple sclerosis

\section{Introduction}

Cortisol is a naturally occurring hormone normally associated with immune protection and the regulation of stress [1-5]. Monitoring the levels of cortisol is often helpful in cases where high levels of stress is present such as adrenal insufficiency, or Cushing's disease and in multiple sclerosis [3], where cortisol levels are thought to fluctuate with continued fatigue.

Yawning and cortisol has been associated with fatigue [6-8] and the Thompson Cortisol Hypothesis was proposed to account for how yawning is triggered by threshold levels of cortisol in order to promote brain cooling [8-10]. The combination of yawning and cortisol has also been proposed as a potential biomarker for the early detection of signs of neurological disease $[11,12]$ with the first electromyogram representation of the yawn being reported [11,13] (Figures 1 and 2) [13].

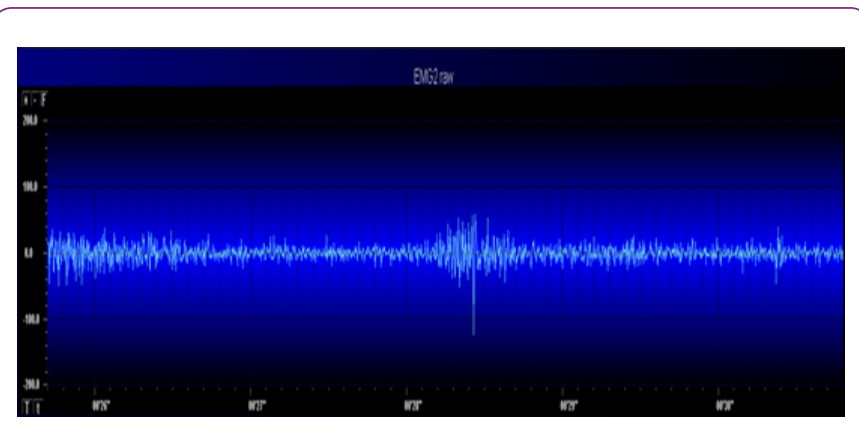

Figure 1 Electrompyogram of the yawn reflex.

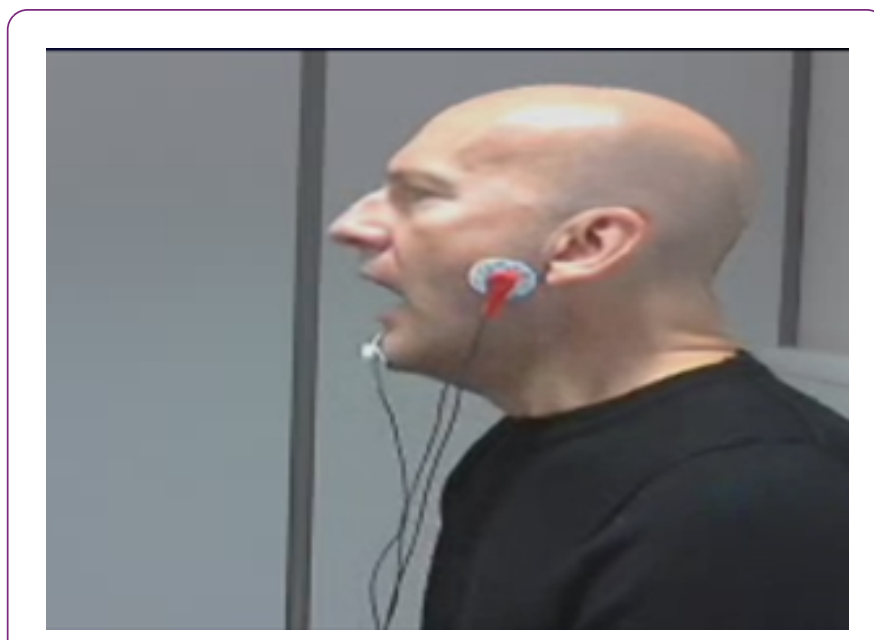

Figure 2 Electromyography recording during yawn reflex.

Researchers have examined potential biomarkers [14]; and in particular, yawning and cortisol have been proposed as biomarkers with further investigations of induced fatigue in healthy subjects showing that certain brain regions are activated during differing levels of cortisol [15]. This has provided support for the notion that yawning is triggered by 
cortisol fluctuations and affects the hypothalamus causing it to lower brain temperature [9].

Temperature regulation and circadian rhythm is the responsibility of the hypothalamus. Within the hypothalamuspituitary-adrenal (HPA) axis, the hypothalamus produces sufficient cortisol releasing hormone to elicit the release of adrenocortiocotropic hormone from the pituitary gland to protect against stress by activating the zona fasciculate in the adrenal glands [16] to secrete cortisol and adrenaline [12]. It is thought that this ultimately feeds back to the hypothalamus to lower brain temperature by triggering a yawn $[9,10,15,17]$.

The curious observations of Sir Francis Walshe, the British Neurologist, in 1923 when he evidenced brain-stem ischaemic stroke patients raising their paralyzed arm when involuntarily yawning [18], gave rise to much examination of stroke patients [19] and the subsequent proposition that the brain-stem region may be intimately linked to the motor cortex because it produces this observed parakinesia brachialis oscitans $[19,20]$.

Interestingly, the brain-stem comprises three main components, the pons, mid-brain, and medulla oblongata [21]. Brain-stem has several important functions including respiratory functioning and cardiac regulation and so is vital to survival. Researchers at the University of Adelaide [22] found that plasticity of human motor cortex is influenced by time of day, and circulating levels of cortisol. The Gammaaminobutyric acid (GABA)-beta receptors are affected (Figure 3) [23]; and particularly, these dependent intracortical inhibitory systems are also influenced by circulating cortisol levels [22].

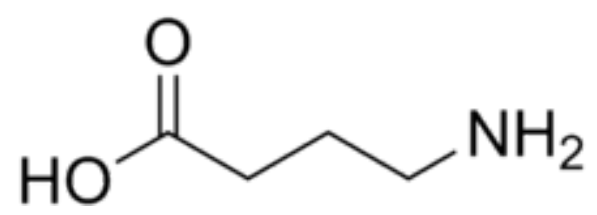

Figure 3 Gamma-aminobutyric acid.

Hasan and colleagues [24] have found that the motor cortex in mice has sophisticated receptors that help play an important role in learned motor responses. For example, during motor learning, synaptic efficacy between sensory and primary motor cortisol neurons is enhanced and possibly involves long-term potentiation and N-methyl-D-aspartate (NMDA)-specific glutamate receptor function. In humans, cortisol-specific receptor sites in the motor cortex may play a larger role in the communication between other brain regions, such as the brain-stem and hypothalamus.

Indeed, the communication between these sites may be less intimately linked by neural networks but rather by chemical (hormone) systems such as the HPA-axis. This would certainly provide a possible understanding of why stroke patients with brain-stem lesions are able to raise an affected arm when yawning.

\section{References}

1. Thompson SBN (2010) The dawn of the yawn: Is yawning a warning? Linking neurological disorders. Med Hyp 75: 630-633.

2. Thompson SBN (2016) Yawning. In: Thompson SBN (ed.), Trauma psychology. Clinical case histories, reviews, research. Portsmouth, Blackwell-Yale-Academic 2016: 355-360.

3. Thompson SBN, Bishop P (2012) Born to yawn? Understanding yawning as a warning of the rise in cortisol levels: randomized trial. Interact J Med Res e4: 1-9.

4. Fleming WE, Pollak CP (2014) Sleep disorders in multiple sclerosis. Sem Neurol 25:64-68

5. Thompson SBN (2014) Yawning, fatigue, and cortisol: expanding the Thompson Cortisol Hypothesis. Med Hyp 4: 494-496.

6. Walker S, Taipale RS, Nyman K, Kraemer WJ, Häkkinen K (2011) Neuromuscular and hormonal responses to constant and variable resistance loadings. Med Sci Sports Exer 1: 26-33.

7. Bresciani G, Cuevas MJ, Molinero O, Almar M, Suay F, et al. (2011) Signs of overload after an intensified training. Int J Sports Med 5: 338-343.

8. Locke S, Osborne M, O'Rourke P (2011) Persistent fatigue in young athletes: measuring the clinical recovery and identifying variables affecting clinical recovery. Scandin J Med Sci Sports 1: 90-97.

9. Thompson SBN (2015) Pathways to yawning: making sense of the Thompson Cortisol Hypothesis. Med Res Arch 3: 1-7.

10. Thompson SBN, Richer S (2015) How yawning and cortisol regulates the attentional network. J Neurosci Rehab 1: 1-9.

11. Thompson SBN (2015) Yawning and cortisol as a potential biomarker for early detection of multiple sclerosis. Int J Med Health Biomed Bioeng Pharma Eng 5: 382-386.

12. Thompson SBN (2016) Diagnostic biomarkers - exploring the potential of cortisol and yawning in the detection of neurological disease processes. J Neurol Neurosci 7:112.

13. Thompson SBN (2013) How to catch a yawn: initial observations of a randomized controlled trial. Neurol 8:1-8.

14. Strimbu K, Jorge $T$ (2010) What are biomarkers? Current Opinion in HIV and AIDS 6: 463-466.

15. Thompson SBN, Daly S, Le Blanche A, Adibi M, Belkhiria C, et al. (2016) fMRI randomized study of mental and motor task performance and cortisol levels to potentiate cortisol as a new diagnostic biomarker. J Neurol Neurosci 7: 92.

16. Schillings WJ (2008) Physiology and tests of adrenal cortisol function. Glob Lib Wom Med.

17. Thompson SBN (2015) Health psychology intervention identifying early symptoms in neurological disorders. Int J Med Health Biomed Bioeng Pharma Eng 4: 351-355.

18. Provine R (2012) Curious behavior: yawning, laughing, hiccupping and beyond. New York, USA: Belknap pp: 31-32

19. Walusinski O, Neau JP, Bogousslavsky J (2010) Hand up! Yawn and raise your arm. Int J Stroke 5: 21-27.

20. Thompson SBN (2011) Is yawning a warning, neurologically? Neurol 2: 1-7.

21. Thompson SBN (2012) Neuroanatomy - A beginner's guide. Saarbrüken: LA 
22. Sale MV, Ridding MC, Nordstrom MA (2008) Cortisol inhibits neuroplasticity in human motor cortex. J Neurosci 33: 8285-8293.

23. GABA receptor (2016) From Wikipedia, the free encyclopedia.
24. Hasan MT, Hernandez GS, Dogbevia G, Trevino M, Bertocchi I, et al. (2013) Role of motor cortex NMDA receptors in learningdependent synaptic plasticity of behaving mice. Nat Comm 2258: 1-9. 